\title{
Medición de la experiencia del turista en Quito
}

\author{
Tourist experience measurement in Quito city
}

\section{Medição da experiência turística em Quito}

\author{
Pablo Aníbal Torres Matovelle ${ }^{1}$ \\ Simone Baez ${ }^{2}$
}

\begin{abstract}
Resumen: Aunque la experiencia del turista ha sido un tema profundamente estudiado, aún permanece latente la necesidad de aplicar nuevos métodos para su medición desde una perspectiva holística. Esta investigación tiene por objetivo medir la experiencia del turista en Quito mediante el método de evaluaciones sumarias a partir de un set integral de dimensiones e indicadores propuestos en la literatura especializada y su disposición gráfica mediante la matriz de análisis de importancia - desempeño. Para ello se realiza un análisis tanto a nivel descriptivo como inferencial, por medio de los cuales se valida una propuesta teórica de dimensiones e indicadores de la experiencia turística, a la vez que se determina la importancia de las dimensiones y el desempeño percibido en ellas por la demanda, identificando los factores influyentes en la satisfacción del turista. El estudio valida el modelo teórico sometido a contraste empírico y demuestra que la experiencia del turista en Quito es altamente satisfactoria e influenciada por veintiún aspectos clave. Finalmente, la investigación determina que en las dimensiones: unicidad, multisensorialidad, calidad racional y desarrollo personal se equilibran las expectativas de los turistas con lo obtenido durante su viaje; mientras que las dimensiones: desarrollo relacional y responsabilidad se perciben por debajo de sus expectativas.
\end{abstract}

Palabras clave: Medición. Experiencia turística. Dimensione. Indicadores. Encuesta.

Resumo: Embora a experiência turística tenha sido um assunto profundamente estudado, a necessidade de aplicar novos métodos para a sua medição a partir de uma perspectiva holística ainda permanece latente. 0 objetivo desta pesquisa é medir a experiência turística em Quito através do método de avaliação resumida com base em um conjunto abrangente de dimensões e indicadores propostos na literatura especializada e sua disposição gráfica através da matriz de análise importância - desempenho. Para fazer isso, uma análise é realizada de forma descritiva e inferencial, através da qual é validada uma proposta teórica de dimensões e indicadores

\footnotetext{
${ }^{1}$ Candidado a PhD. Facultad de Turismo de la Universidad de la Habana. Universidad Tecnológica Equinoccial. Ecuador. Ffue responsable de la concepción y diseño general de esta investigación. Realizó el análisis multivariado y la interpretación de los datos así como el análisis de importancia/desempeño. Se encargó de redactar los sucesivos borradores del artículo según las recomendaciones de los jueces.

${ }^{2}$ Investigadora independiente. Ecuador. Fue responsable del levantamiento de los datos y el análisis descriptivo. Adicionalmente contribuyó a la dirección conceptual y el diseño de la investigación. Los cuestionarios se levantaron durante el desarrollo de su tesis de investigación de ingeniería que fue dirigida por el co-autor. El tratamiento de los datos colectados y el análisis que se presentan en este documento corresponden a una nueva investigación independiente de los autores.
}

Artículo recibido en: 18/09/2017. Artículo aceptado en: 31/01/2018. 
da experiência do turismo, determinando a importância das dimensões e do desempenho percebido nelas, identificando os fatores influentes na satisfação do turista. O estudo valida o modelo teórico sujeito ao contraste empírico e mostra que a experiência turística em Quito é altamente satisfatória e influenciada por vinte e um aspectos-chave. Finalmente, a pesquisa determina que, nas dimensões: singularidade, qualidade multisensorial, qualidade racional e desenvolvimento pessoal, a experiência é equilibrada com as expectativas dos turistas durante a viagem; enquanto as dimensões: desenvolvimento e responsabilidade relacionais, experiência são percebida abaixo das expectativas.

Palavras-chave: Medição. Experiência turística. Dimensão. Indicadores. Inquérito.

Abstract: Although tourist experience has been a deeply studied subject, the need to apply new methods to measure it from a holistic perspective still remains latent. This research aims to measure tourist experience in Quito through Likert-type scales on a comprehensive set of dimensions and indicators proposed in the specialized literature, and their graphic disposition through the importance - performance analysis matrix. To do this, a multivariate analysis is carried out and a theoretical proposal of dimensions and indicators of tourism experience is validated. Thus, this study determine the importance of each dimension and the performance perceived in them by tourist, identifying the influential factors about tourist satisfaction. The study validates the theoretical model subjected to empirical contrast and shows that tourist experience in Quito is highly satisfactory and influenced by twenty key aspects. Finally, research determines that tourist's expectations in the dimensions: uniqueness, multisensorily, rational quality and personal development, are balanced with what they obtained during their trip; on the other side, performance related to dimensions relational development and responsibility are perceived below their expectations.

Keywords: Measurement. Tourism experience. Dimensions. Indicators. Survey.

\section{INTRODUCCIÓN}

Es ampliamente reconocido que en la dinámica del mercado turístico ya no se trata de ofrecer únicamente productos o servicios sino experiencias, a fin de que los turistas se conviertan en clientes fieles $y$ además en prescriptores (Fuste y Nava, 2015), por tanto el reporte de la experiencia es un dato fundamental en la planeación y evaluación turística (Hernández, Vargas y Aguilar, 2015) en razón de que ofrecer experiencias de calidad constituye una condición fundamental para ser competitivo en la industria del turismo (Sernatur, 2016).

En este contexto, la relevancia que tiene el conocimiento de la experiencia turística se ha visto reflejada en la investigación aplicada. De acuerdo con Tussyadiah
(2014) la reciente producción de publicaciones científicas tiende a mostrar a la experiencia del turista como la esencia de turismo. En esa misma línea de pensamiento Bosangit, Hibbert y McCabe (2015), señalan que el análisis de la experiencia ha llegado a ser una de las áreas de estudio más significativas en la investigación turística; y de hecho, la literatura académica sobre el tema se ha enriquecido de nuevas voces provenientes de regiones distintas a la tradicional angloparlante del Atlántico Norte (Ryan, 2010). Sin embargo, rescatando lo referido por Oakeshot en 1933, la experiencia es la palabra más difícil de manejar de todas en el vocabulario filosófico y lo propio puede llevarse al plano de la experiencia en el turismo. Actualmente, a pesar de la riqueza de trabajos, la evidencia empírica 
permanece débil y en la medida en que avanza el conocimiento sobre las dimensiones, determinantes y consecuencias de la experiencia turística, igualmente se requieren mejorar los métodos y enfoques de investigación (Ingram, Caruana y McCabe; 2017).

Atendiendo a ello, esta investigación tiene por objetivo la medición de la experiencia del turista mediante un enfoque cuantitativo, haciendo uso de la técnica de la encuesta y la matriz de análisis importancia - desempeño. El lugar de estudio es Quito, destino emblemático del Ecuador por haber ganado durante cuatro años consecutivos el reconocimiento del "Word Travel Award" en la categoría Destino Líder de Sudamérica. El estudio es de especial interés en razón de ser pionero en el análisis de la experiencia del turista en la ciudad desde una perspectiva holística y de particular utilidad como soporte a la toma de decisiones en materia de estructuración de oferta y gestión de destino. El presente artículo se basa parcialmente en un trabajo de tesis de grado realizado y dirigido recientemente por los autores, mismo que ha sido complementado con un análisis multivariante.

\subsection{Revisión de literatura}

\subsubsection{La experiencia del turista en destino}

Como lo señalan Hossany y Gilbert (2014) los destinos turísticos están mejor preparados para el éxito si reconocen la calidad de la experiencia en sus ofertas. La conciencia de esta realidad, ha promovido un auge de la investigación en este ámbito.
La experiencia del consumidor ha sido objeto de profusos estudios dado que su conocimiento proporciona sustancial apoyo a la toma de decisión en el campo del marketing; no obstante de ello aún su conceptualización y medición son todavía ambiguos.

En el plano turístico y a una escala de análisis territorial, la experiencia turística puede expresarse de una manera muy simple como en la definición de Sharpley y Stone (2011) donde constituye lo que el turista experimenta; y de formas más desarrolladas como se cita a continuación:

- La experiencia turística es un evento relacionado a un viaje personal pasado, lo suficientemente fuerte para entrar en la memoria de largo plazo (Larsen, 2007)

- La experiencia de un turista consiste en un continuo flujo de servicios integrados y relacionados los cuáles son adquiridos durante un periodo de tiempo limitado, con frecuencia en diferentes áreas geográficas (Mendes et al., 2010).

- La experiencia turística es un conjunto de impresiones físicas, emocionales, sensoriales, espirituales y/o intelectuales, que son percibidas de manera diferente por los turistas, desde el mismo momento en que planifican su viaje, lo disfrutan en el destino elegido e incluso cuando vuelven a su lugar de origen y recuerdan su viaje (Otto and Ritchie, 1995 citado por Rivera, 2013).

- La experiencia es una vivencia perso- 
nal, reflejo de aspectos tangibles e in tangibles que impactan y sufren el impacto de acontecimientos únicos y memorables (Rivera, 2013).

- La experiencia turística se trata de un proceso acumulativo que incluye las fases: anterior, vacacional en el destino y posterior a las vacaciones; $y$ que necesita de una preparación explícita para que suceda (Carballo, et al. (2015).

- La experiencia en destino es la impresión multidimensional que un turista se lleva, y que está formada por diferentes componentes de difícil determinación (Karayilan y Cetin, 2016).

De acuerdo con esto, puede afirmarse que la experiencia turística en destino tiene lugar en la mente del turista a través de un proceso de fijación y agregación de impresiones sensoriales, cognitivas, y emocionales en un periodo de viaje que va desde su planificación hasta su rememoración. De acuerdo con Pine y Gilmore (1998) las experiencias pueden agruparse en cuatro categorías: de entretenimiento, educativas, estéticas y escapistas; en cambio para Aho (2001) se distinguen experiencias informativas, emocionales, prácticas y transformadoras.

La experiencia del viajero en destino como un constructo multidimensional, ha merecido la atención de numerosos expertos quienes han adicionado paulatinamente variables a ser consideradas como parte del mismo. Así, a la propuesta temprana de Otto y Ritchie (1996) que plantean las variables: hedonismo, involucramiento, paz mental y reconocimiento; se han ido sumando otras como: amor, diversión, sorpresa positiva (Hosany y Gilbert; 2010); involucramiento, intemporalidad, felicidad, placer, relajación, estimulación, espontaneidad, significado, sentido de alejamiento, aventura, relevancia personal, novedad, cultura local, presión y cultivo intelectual (Kim, Ritchie y McCormick, 2010); libertad de elección, fantasía, espontaneidad, entretenimiento especial, sentimientos de autorrealización (Nash \& Smith, 1991, citados por Rivera M. , 2012); sentimientos adversos (Kim, 2014); características auténticas del destino y patrimonio cultural (Cetin \& Bilgihan, 2015), entre otras. Destacan sin embargo en esta misma línea, el planteamiento de Pulido \& Navarro (2014) quienes proponen un bloque integrado de factores e indicadores para medir las experiencias del turista en destino, que abarcan aspectos sociales, emocionales, sensoriales, creativos, relacionales, cognitivos y personales. Los nueve factores que miden la experiencia turística desde el punto de vista de estos autores, se puede ver en la tabla 1. 
Tabla 1 - Dimensiones e indicadores de la experiencia turística

\begin{tabular}{|c|c|}
\hline Factores & Índicadores \\
\hline \multirow{16}{*}{$\begin{array}{l}\text { Motivación personal para su } \\
\text { comunicación social }\end{array}$} & Recursos únicos \\
\hline & Historia singular del lugar \\
\hline & Clima particular \\
\hline & Producto turístico ínimitable \\
\hline & Calidad única medio ambiental \\
\hline & Comidas carácteristicas del lugar \\
\hline & Singular idiosincrasia de los habitantes de la zona \\
\hline & Prestigio \\
\hline & Orgullo \\
\hline & Estatus social \\
\hline & Apariencia \\
\hline & Honor \\
\hline & Respeto \\
\hline & Reputación \\
\hline & Riesgo/Peligro/Miedo \\
\hline & Autorrealización \\
\hline \multirow[t]{2}{*}{ Co-creación } & Grado de participación del cliente \\
\hline & Posibilidad adaptar el producto en tiempo real \\
\hline \multirow{4}{*}{ Multisensorialidad } & Sensación de satisfacción \\
\hline & Sensación de bienestar \\
\hline & Valoración positiva/negativa de las sensaciones \\
\hline & Valoración positiva/negativa de los sentidos \\
\hline \multirow{6}{*}{$\begin{array}{l}\text { Entretenimiento y Capacidad } \\
\text { Lúdica }\end{array}$} & Actividades recreativas y deportivas \\
\hline & Aire libre y naturaleza \\
\hline & Diversión y disfrute \\
\hline & Ambiente de fiesta \\
\hline & Conciertos y espectaculos \\
\hline & Arte y cultura \\
\hline \multirow[t]{7}{*}{ Desarrollo personal } & Aprendizaje y educación \\
\hline & Interés cultural \\
\hline & Ampliar horizontes \\
\hline & Necesidades afectivas cubiertas \\
\hline & Necesidades autorealización cubiertas \\
\hline & Enriquecimiento cultural \\
\hline & Inteligencia emocional \\
\hline \multirow{7}{*}{$\begin{array}{l}\text { Desarrollo Relacional } \\
\text { Calidad Racional }\end{array}$} & Interacción social \\
\hline & Precios asequibles \\
\hline & Comodidad del viaje \\
\hline & Ubicaciones fáciles de encontrar \\
\hline & Prácticos transportes públicos \\
\hline & Atributos de los servicios a consumir \\
\hline & Profesionalidad y competencias en la atención \\
\hline \multirow[t]{3}{*}{ Responsabilidad } & Integridad \\
\hline & Discciplina \\
\hline & Reciprosidad \\
\hline
\end{tabular}

Fuente: (Pulido Fernández \& Navarro Hermoso, 2014); Elaboración: Autores 


\subsubsection{La medición de las experiencias turís- ticas en destino}

Citando a Burns \& Holden (1995), la medición de la experiencia integral en destinos es más complejo que a nivel de servicios individuales. Carballo et al. (2015) acotan que debido a que la mayoría de experiencias en turismo tienen lugar en un corto periodo con episodios ininterrumpidos, puede ser difícil alcanzar una verdadera comprensión de las mismas; y enumeran entre los esfuerzos que se han desarrollado para estudiar la experiencia turística, los realizados por Nickerson (2004) a través del diario de composición abierta, encuestas por correo y entrevistas en profundidad;

Lee et al. (1994) a través del método de cinta de grabación por iniciativa propia y entrevistas en profundidad; Jackson et al. (1996) quienes utilizaron la técnica de incidentes; Carlzon, (1987) y el análisis de los momentos críticos de la verdad; Schmitt (2003) y el mapa de la experiencia; Harris et al. (2003) y el desarrollo del guión teatral; entre otros de corte cualitativo. Recalcan sin embargo la necesidad de nuevas formas de investigación aplicadas al estudio de la experiencia turística. Esto es especialmente necesario desde un enfoque cuantitativo, donde observa limitaciones importantes para comprender en profundidad su naturaleza y valoración.

En los últimos cinco años, han habido aportes importantes al estudio de la experiencia turística: Prayag, Hosany y Odeh (2013) estudiaron la relación entre las experiencias emocionales, la satisfacción y las intenciones de comportamiento en Petra-Jordania con base en una encuesta; en otra línea Bosangit, Hibbert y McCabe (2015) realizaron el estudio de la experiencia turística a partir del análisis de contenido de blogs de viajeros en el Reino Unido; mientras que Park y Almeida (2016) realizaron 28 entrevistas semiestructuradas a turistas coreanos para determinar los elementos centrales de la experiencia turística memorable en las tres estaciones temporales del viaje (pre-durante y post viaje). Ingram, Caruana y McCabe (2017) aplicaron la consulta participante en una selección de 16 turistas cuyo destino varió entre doméstico, europeo e internacional, igualmente en su proceso completo de realización. Finalmente Wearing y Foley (2017) estudiaron el movimiento de los turistas a través de la ciudad para comprender sus experiencias desde una perspectiva que reivindica la escasa visibilidad dada al género femenino en la investigación turística.

\section{METOdOLOGÍA}

Este estudio de tipo empírico se desarrolló mediante la aplicación de una encuesta a una muestra de turistas extranjeros mayores de 18 años de edad, que visitaron la ciudad de Quito a lo largo del mes de marzo de 2017. Se calculó una muestra de 384 personas, considerando un margen de error de $+/-5 \%$ y un nivel de confianza del $95 \%$, no obstante se obtuvieron 402 cuestionarios válidos.

La encuesta fue aplicada con posterioridad a la visita con el objeto de obtener 
respuestas basadas en una percepción global de la experiencia turística obtenida en Quito. Por ello, los individuos fueron entrevistados durante su estancia en la ciudad para obtener sus datos de contacto electrónico y fecha prevista de salida del país. Posterior a esa fecha se les envío una invitación a participar de la encuesta, la cual estuvo ingresada en línea en la plataforma Google.

El cuestionario se estructuró en dos apartados; el primero contuvo nueve preguntas de opción múltiple y una abierta, orientadas a obtener información sociodemográfica; el segundo contuvo 54 preguntas con una escala Likert de cinco puntos (desde muy bajo hasta muy alto), para medir importancia de dimensiones y valoración de indicadores de experiencia, tomando como base la propuesta de factores e indicadores de la experiencia turística de Pulido y Navarro (2014).

Se realizó una prueba piloto entre el 17 y el 28 de febrero de 2017, con 55 encuestas con el objeto de validar los cuestionarios, comprobándose la fiabilidad del instrumento mediante el coeficiente Alpha de Cronbach que se calculó en 0,86 ., considerado válido por Nunnally \& Bernstein (1994).

Los datos colectados fueron tabulados y analizados mediante el programa IBM SPSS Versión 24. El análisis de los datos se realizó a nivel descriptivo e inferencial. Para este último nivel se aplicaron varias pruebas estadísticas con diferentes objetivos: un análisis factorial confirmatorio para validar las dimensiones e indicadores propuestos por Pulido y Navarro (2014); un Anova de un factor con análisis post hoc mediante la prueba de Tukey, para establecer diferencias estadísticas significativas en la valoración de importancia entre dimensiones, y coeficientes de correlación Ji-cuadrado y Spearman para establecer dependencia entre variables. Finalmente se elaboró una matriz de importancia - desempeño para contrastar lo esperado versus lo obtenido en torno a la experiencia del turista en Quito desde su propia perspectiva.

\section{RESULTADOS}

\subsection{Perfil del turista encuestado}

El perfil del turista extranjero muestra diversidad de nacionalidades entre las que destacan por su mayor frecuencia las siguientes: estadounidense $(25,1 \%)$, alemana $(12,7 \%)$, argentina $(8,5 \%)$, colombiana $(8 \%)$, británica (7,5\%) y canadiense (6\%). Entre los rasgos del perfil que sobresalen igualmente por su mayor frecuencia se encuentran: la edad comprendida entre los 26 y 35 años (34,3\%), el nivel educativo universitario $(74,1 \%)$, el estado civil soltero $(60,9 \%)$, la ocupación en el ámbito profesional $(64,7 \%)$, la organización de viaje por cuenta propia $(78,1 \%)$, el gasto diario promedio entre 16 y 50 dólares norteamericanos y la estancia promedio entre 1 y 3 días. Un mayor detalle del perfil se expone en la tabla 2. 
Tabla 2 - Variables sociodemográficas del turista encuestado

\begin{tabular}{|c|c|c|c|c|c|}
\hline \multicolumn{2}{|l|}{ Variable } & \multirow{2}{*}{$\begin{array}{r}\% \\
48,5\end{array}$} & \multicolumn{2}{|c|}{ Variable } & \multirow{2}{*}{$\begin{array}{c}\% \\
25,1\end{array}$} \\
\hline Sexo & Hombre & & Nacionalidad & $\begin{array}{l}\text { Estados Uni- } \\
\text { dos }\end{array}$ & \\
\hline & Mujer & 51,5 & & Gran Bretaña & 7,5 \\
\hline \multirow[t]{5}{*}{ Edad } & Menor de 25 años & 27,4 & & Alemania & 12,7 \\
\hline & Entre 26 y 35 años & 34,3 & & Argentina & 8,5 \\
\hline & Entre 36 y 45 años & 12,2 & & Venezuela & 4,5 \\
\hline & Entre 46 y 65 años & 24,6 & & Colombia & 8,0 \\
\hline & Más de 66 años & 1,5 & & Suiza & 1,5 \\
\hline \multirow[t]{3}{*}{ Nivel educativo } & Colegio & 4,5 & & Sudáfrica & 0,7 \\
\hline & Universidad & 74,1 & & Canadá & 6,0 \\
\hline & Posgrado & 21,4 & & China & 2,5 \\
\hline \multirow[t]{5}{*}{ Estado Civil } & Soltero & 60,9 & & México & 1,7 \\
\hline & Casado & 32,6 & & Australia & 2,7 \\
\hline & Unión Libre & 1,7 & & Chile & 3,0 \\
\hline & Divorciado & 1,5 & & Guatemala & 1,0 \\
\hline & Viudo & 3,2 & & Perú & 1,2 \\
\hline \multirow[t]{3}{*}{$\begin{array}{l}\text { Organización de } \\
\text { viaje }\end{array}$} & $\begin{array}{l}\text { Organizado por agencia } \\
\text { de viaje }\end{array}$ & 21,9 & & Brasil & 0,7 \\
\hline & Por cuenta propia & 78,1 & & Cuba & 0,2 \\
\hline & Hasta US\$D 25 & 10,7 & & Jamaica & 0,5 \\
\hline \multirow[t]{4}{*}{ Gasto diario } & Entre US\$ 26 a US\$ 50 & 34,6 & & Uruguay & 2,2 \\
\hline & Entre USD 51 a USD 75 & 28,4 & & Dinamarca & 1,0 \\
\hline & Entre US\$ 76 a US\$ 100 & 17,9 & & España & 1,0 \\
\hline & Más de US\$ 100 & 8,5 & & Holanda & 3,5 \\
\hline \multirow[t]{5}{*}{ Ocupación } & Estudiante & 25,1 & & Francia & 1,0 \\
\hline & Profesional & 64,7 & & Bélgica & 0,7 \\
\hline & Retirado & 8,7 & & Filipinas & 0,5 \\
\hline & Ama de casa & 0,5 & & El Salvador & 0,5 \\
\hline & Desempleado & 1,0 & & Costa Rica & 1,2 \\
\hline \multirow[t]{4}{*}{ Estadía } & De 1 a 3 días & 41,5 & & Bolivia & 0,2 \\
\hline & De 4 a 7 días & 28,9 & & Total & 100,0 \\
\hline & De 8 a 11 días & 6,0 & & & \\
\hline & 12 días o más & 23,6 & & & \\
\hline \multirow[t]{5}{*}{ Grupo de Viaje } & Grupo familiar & 16,7 & & & \\
\hline & Grupo de amigos & 42,3 & & & \\
\hline & Grupo de trabajo & 6,0 & & & \\
\hline & Pareja & 16,4 & & & \\
\hline & Solo & 18,7 & & & \\
\hline
\end{tabular}

Elaboración: Autores

\subsection{Confirmación de dimensiones de la ex- periencia turística}

El análisis factorial confirmatorio mediante el método de extracción de componentes principales usando rotación Varimax con Kayser, aplicado a las dimensiones planteadas en el modelo teórico de Pulido y Navarro (2014), demuestra que al menos un $84,4 \%$ de los indicadores propuestos se aglomeran en las dimensiones propuestas, confirmándose en ese sentido la pertinencia de las mismas de manera empírica en el contexto de la ciudad de Quito con turistas extranjeros. Así, se encuentra que de todos los ítems planteados por los autores referidos, apenas 7 no se emparejan en las dimensiones planteadas. El detalle de los valores calculados se muestra en la tabla 3. 
Tabla 3 - Matriz de componentes rotados

\begin{tabular}{|c|c|c|c|c|c|c|c|c|c|}
\hline \multirow{2}{*}{ Indicador } & \multicolumn{9}{|c|}{ Componente } \\
\hline & 1 & 2 & 3 & 4 & 5 & 6 & 7 & 8 & 9 \\
\hline Motivación - Respeto & ,785 & & & & & & & & \\
\hline Motivación - Honor & ,783 & & & & & & & & \\
\hline Motivación - Reputación & 783 & & & & & & & & \\
\hline Motivación - Prestigio & ,745 & & & & & & & & \\
\hline Motivación - Orgullo & ,727 & & & & & & & & \\
\hline Motivación - Auto realización & 434 & & & & & & & & \\
\hline Calidad Racional - Fácil localización & & ,705 & & & & & & & \\
\hline Calidad Racional - Profesionalismo y habilidades en el servicio al cliente & & ,704 & & & & & & & \\
\hline Calidad Racional - Confort de viaje & & 684 & & & & & & & \\
\hline Entretenimiento - Afueras y naturaleza* & &, 579 & & & & & & & \\
\hline Calidad Racional - Atributos del servicio & & ,566 & & & & & & & \\
\hline Calidad Racional - Precios asequibles & & ,421 & & & & & & & \\
\hline Unicidad - Calidad ambiental única & & & 691 & & & & & & \\
\hline Unicidad - Clima particular & & & ,646 & & & & & & \\
\hline Unicidad - Producto turístico inimitable & & & ,598 & & & & & & \\
\hline Unicidad - Ideosincracia única & & &, 594 & & & & & & \\
\hline Unicidad - Recursos únicos & & &, 593 & & & & & & \\
\hline Unicidad - Comidas características del lugar & & &, 512 & & & & & & \\
\hline Unicidad - Historia singular & & & ,483 & & & & & & \\
\hline Multisensorialidad - Sensasión de satisfacción & & & &, 761 & & & & & \\
\hline Multisensorialidad - Sensasión de bienestar & & & &, 710 & & & & & \\
\hline Multisensorialidad . Sentimientos positivos & & & & ,701 & & & & & \\
\hline Multisensorialidad - Sensasiones positivas & & & & 670 & & & & & \\
\hline Entretenimiento - Arte y cultura* & & & & ,331 & & & & & \\
\hline Desarrollo Personal - Intereses culturales & & & & & ,717 & & & & \\
\hline Desarrollo Personal - Expandir horizontes & & & & & 659 & & & & \\
\hline Desarrollo Personal - Educación y aprendizaje & & & & & 649 & & & & \\
\hline Desarrollo Personal - Enriquecimiento cultural & & & & & 611 & & & & \\
\hline Desarrollo Personal - Neceisdades de auto realización cubiertas & & & & & 609 & & & & \\
\hline Desarrollo Personal - Necesidades afectivas cubiertas & & & & &, 601 & & & & \\
\hline Entretenimiento - Atmósfera de fiesta & & & & & & ,758 & & & \\
\hline Entretenimiento - Shows y conciertos & & & & & & 629 & & & \\
\hline Entretenimiento - Actividades deportivas y recreacionales & & & & & &, 578 & & & \\
\hline Entretenimiento - Diversión y disfrute & & & & & &, 529 & & & \\
\hline Calidad Racional - Transportación pública práctica* & & & & & &, 522 & & & \\
\hline Desarrollo Relacional - Interacción social* & & & & & & 473 & & & \\
\hline Responsabilidad - Integridad & & & & & & & 822 & & \\
\hline Responsabilidad - Disciplina & & & & & & & ,797 & & \\
\hline Responsabilidad - Reciprocidad & & & & & & & ,726 & & \\
\hline Motivación - Apariencia* & & & & & & & & ,638 & \\
\hline Motivación - Riesgo, peligro, miedo* & & & & & & & & 619 & \\
\hline Motivación - Status* & & & & & & & & 618 & \\
\hline Desarrollo Personal - Inteligencia emocional & & & & & & & &, 591 & \\
\hline Co-creación - En la provisión, creación, difusión, consumo del servicio o producto & & & & & & & & & ,751 \\
\hline Co-creación - Posibilidad de adaptar el producto a mis preferencias en tiempo real & & & & & & & & &, 728 \\
\hline
\end{tabular}


3.3 Valoración de importancia de dimensiones

La valoración de importancia dada a las dimensiones por los turistas encuestados muestra valores distintos como puede no- tarse en la tabla 4, donde se exponen los estadígrafos de posición media, moda y mediana. Como puede verse, la dimensión valorada con el puntaje más alto fue multisensorialidad mientras que la valorada con menor puntaje fue co-creación.

Tabla 4 - Estadígrafos de posición de la valoración de importancia de dimensiones

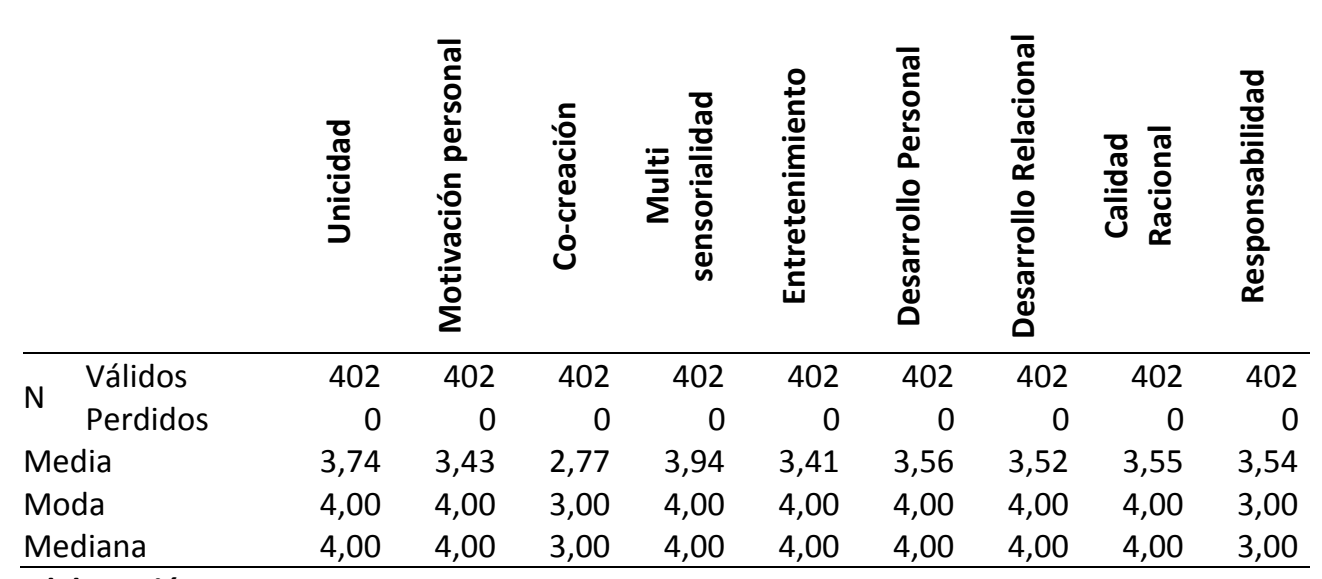

Elaboración: Autores

El Analisis de Varianza confirma que existen diferencias estadísticas significativas en las valoraciones de importancia. Llevando más en profundo el análisis, la prueba de Tukey demuestra una amplia variabilidad en la valoración de importancia dada a las dimensiones, notándose que no existe diferencia estadística en apenas 8 combinaciones de 64 posibles. Las 8 mencionadas se exponen en la tabla 5.

Tabla 5 - Comparaciones múltiples - Prueba de Tukey

\begin{tabular}{lll}
\hline (I)Grupo & (J)Grupo & Sig. \\
\hline \multirow{2}{*}{ Unicidad } & Motivación & 1,00 \\
Motivación & Desarrollo Personal & 1,00 \\
\multirow{2}{*}{ Multisensorialidad } & Desarrollo Personal & 1,00 \\
& Entretenimiento & 0,06 \\
Entretenimiento & Calidad Racional & 0,99 \\
Desarrollo Relacional & Desarrollo Relacional & 1,00 \\
& Calidad Racional & 0,35 \\
& Calidad Racional & 0,19 \\
\hline
\end{tabular}

Elaboración: Autores

Por su parte, los indicadores que integran cada dimensión y que en conjunto determinan la experiencia del turista en Quito, obtuvieron valoraciones diversas a nivel de moda y mediana, notando que más de la mi- tad obtuvo una puntuación de 4 que representa un valor alto. Destacan los indicadores historia singular del lugar, arte y cultura, cuya apreciación por parte de los turistas encuestados fue muy alta. Por el contrario, so- 
bresalen por su muy baja valoración con apeporte público, conciertos y shows. Un detalle nas 1 punto, el grado de participación del tumás amplio de esta valoración se expone en rista en el servicio / producto; y con 2 puntos la figura 1 , a continuación.

(bajo), los ítems: atmósfera de fiesta, trans-

Figura 1 - Valoración de la experiencia turística en Quito por indicadores con base en la mediana de las respuestas obtenidas

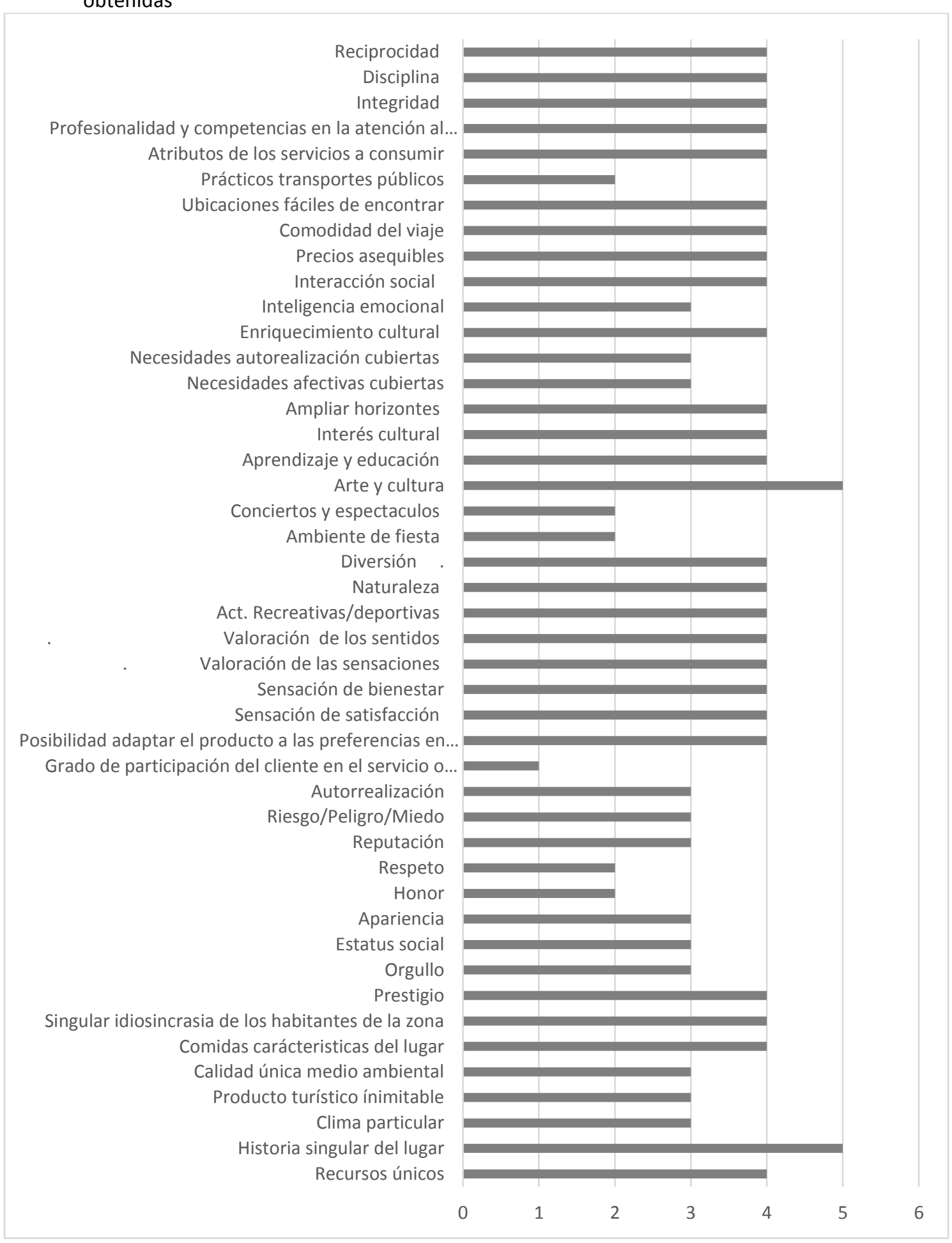




\subsection{Análisis de independencia de variables}

El análisis de independencia de variables mediante el coeficiente Ji-cuadrado de Pearson confirma que la variable género muestra relación con las variables: duración de la estadía, grupo de viaje y gasto diario. Al respecto se encuentra que la estadía mayormente mencionada por las mujeres es la más extensa (12 días o más) mientras que la más seleccionada por hombres es la más corta (13 días). En tanto hombres y mujeres coinciden en seleccionar con mayor frecuencia la categoría amigos como grupo de viaje, la segunda preferencia mayormente seleccionada por hombres es "solo" y por mujeres "familia". En cuanto al gasto diario, los hombres preferentemente gastan más que las mujeres con un promedio diario entre 51 y 75 dólares norteamericanos mientras las mujeres entre 26 y 50 norteamericanos.

La variable edad tiene relación con estadía, grupo de viaje y gasto diario. De ahí que las personas más jóvenes (menores a 25 años) seleccionan con mayor frecuencia la estadía más larga, mientras que las personas a partir de los 26 años de edad prefieren la estadía más corta ( 1 a 3 días). Así también, el grupo de viaje preferente para las personas hasta los 35 años de edad es "amigos", y "pareja" a partir de los 36 años de edad. En cuanto al gasto diario, se puede notar que en la medida en que la edad aumenta, la preferencia por el tour organizado es mayor.

La variable nivel educativo muestra dependencia con las variables estadía y gasto diario. De esta manera se encuentra que las personas con educación secundaria permanecen un mayor número de días, en cambio las personas con un mayor nivel educativo permanecen menos tiempo (mayoritariamente entre 1 y 3 días). Así también, se encuentra que a mayor nivel educativo mayor gasto.

La variable estado civil tiene dependencia con la variable estadía. En ese sentido, se observa que las personas viudas permanecen más tiempo (12 o más días) que las solteras, y éstas últimas permanecen más tiempo (3-7 días) que las casadas.

La variable ocupación guarda relación con la variable gasto diario. Al respecto, se encuentra que el rango de gasto más frecuente para estudiantes es de 26 a 50 dólares norteamericanos, y para profesionales asciende a 51-75 dólares norteamericanos, llegando hasta el rango de 76 a 100 dólares norteamericanos para personas retiradas.

La variable nacionalidad guarda dependencia con las variables: estadía, grupo de viaje, gasto diario y modo de viaje. Respecto a la estadía se encuentra segmentos donde predomina la afinidad por las estancias cortas: canadienses, británicos, australianos y suizos; mientras que para otros segmentos como estadounidenses, alemanes, colombianos, chinos y venezolanos las estancias largas son preferentes. En cuanto al grupo de viaje, los segmentos de nacionalidad estadounidense, alemana y argentina muestran que la compañía de viaje preferente es "en amigos", mientras que para otros segmentos la preferencia es por viajar "en familia": venezolana y colombiana; y finalmente en las nacionalidades canadiense y australiana se presenta mayor preferencia por viajar en pareja. En torno al gasto diario, las personas de nacionalidad estadouniden- 
se, china, venezolana y colombiana muestran mayor frecuencia de selección en el rango comprendido entre 26 y 50 dólares norteamericanos, los argentinos menos de 25 dólares norteamericanos, a diferencia de los ciudadanos alemanes, australianos, peruanos y uruguayos que indicaron gastar con mayor frecuencia entre 51 y 75 dólares norteamericanos; finalmente las personas de nacionalidad británica señalaron gastar con mayor frecuencia entre 76 y 100 dólares norteamericanos. En cuanto a la modalidad de viaje, se nota que las personas de nacionalidad belga, canadiense, británica y australiana, muestran mayores frecuencias de selección en la modalidad de viaje "tour organizado".

Finalmente, se confirmó dependencia entre las variables estadía y gasto diario, notando que a mayor estancia menos gasto diario. La tabla 6 expone esta relación entre variables y el valor de significancia resultante en el cálculo de Ji-cuadrado.

$\underline{\text { Tabla } 6 \text { - Prueba de independencia con base en estadístico Ji- cuadrado }}$

\begin{tabular}{lll}
\hline Variable & Variable & Sig. \\
\hline Género & Estadía & .000 \\
& Grupo de viaje & \\
& Gasto diario & .008 \\
Edad & Estadía & .000 \\
& Grupo de viaje & \\
Nivel educativo & Gasto diario & \\
& Estadía & \\
Estado civil & Gasto diario & \\
Ocupación & Estadía & \\
Nacionalidad & Gasto diario & \\
& Estadía & \\
\hline
\end{tabular}

Elaboración: Autores

Por otra parte, el resultado del análisis de independencia mediante el coeficiente de correlación de rangos, confirma que existe un conjunto de variables que muestran mayor influencia en la valoración de importancia de las dimensiones bajo estudio. Estas son: género, edad, nivel educativo, estado civil, ocupación, estadía, gasto diario, y modo de viaje.

En este conjunto destacan las variables: "edad" y "nivel educativo" por ser las que influencian la mayor cantidad de dimensiones (siete); seguidas de "estado civil", "gasto diario", y "modo de viaje" (cinco dimensiones); y "ocupación" y "estadía” (cuatro dimensiones). Finalmente la variable "género" influye en una sola dimensión. Cabe notar que para la dimensión "atributos especiales y únicos del destino" las variables citadas no muestran dependencia.

Ampliando el análisis se encuentra que las variables que tienen mayor influencia en la dimensión "oportunidades para las relaciones sociales" son: género, edad, nivel educativo, estado civil, gasto diario y modo de viaje. En cambio, para la dimensión “expe- 
riencias de valor para ser contadas" las variables más influyentes son edad y estadía.

En el caso de la dimensión "participación en el diseño, ejecución y/o difusión de servicios y actividades turísticas", se muestra una sola variable influyente que es nivel educativo; en tanto para la dimensión "sensaciones y emociones durante el viaje" las variables influyentes son numerosas: edad, nivel educativo, estado civil, ocupación, estadía, gasto diario y modo de viaje.

La dimensión "actividades y oportunidades para el entretenimiento" se ve mayormente influenciada por las variables edad, nivel educativo, estado civil, ocupación y gasto diario; mientras que para la dimensión "oportunidades para el crecimiento personal" se determinan influyentes las variables: edad, nivel educativo, estado civil, gasto diario y modo de viaje.

En el caso de la dimensión "oportunidades para las relaciones sociales", todas las variables resultaron influyentes. En la dimensión "calidad de servicios" las variables con mayor influencia son todas excepto género y finalmente para la dimensión "práctica de valores personales" las variables influyentes son edad, nivel educativo y modo de viaje. El detalle de este análisis y los valores calculados se exponen en la tabla 7.

Por otra parte, el análisis de independencia de variables aplicado a los indicadores de la experiencia turística en Quito mediante el coeficiente de correlación de rangos, confirma la influencia de las variables: nacionalidad, nivel educativo, estado civil, estadía, grupo de viaje y gasto diario, de manera diferente. Destaca en el conjunto, la variable gasto diario que resulta influyente en el $80 \%$ de los indicadores, seguida de las variables: nivel educativo (60\%), estadía (56\%), estado civil (51\%), nacionalidad (47\%), y grupo de viaje (9\%).

A nivel específico, el estudio muestra que la variable grupo de viaje resulta influyente en aspectos de la experiencia del turista. En ese sentido se encuentra que la constitución del grupo de viaje influye en la "participación del turista en la provisión, creación, difusión y/o consumo de servicios y productos turísticos", así como en el "entretenimiento basado en la naturaleza y los exteriores"; y en las "necesidades afectivas cubiertas". Los valores calculados del coeficiente de Spearman se pueden apreciar en la tabla 8. 
Tabla 7 - Correlación de Spearman entre variables seleccionadas y dimensiones bajo estudio

\begin{tabular}{|c|c|c|c|c|c|c|c|c|c|}
\hline Variable & & 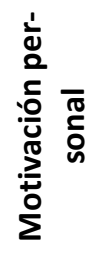 & 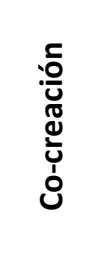 & 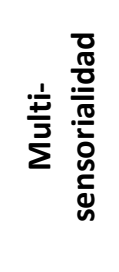 & 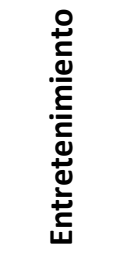 & 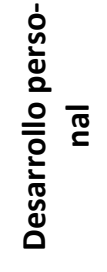 & 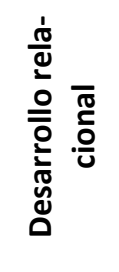 & 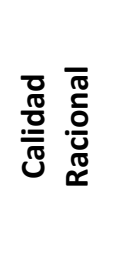 & 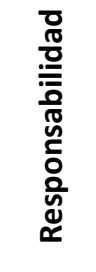 \\
\hline \multirow[t]{2}{*}{ Género } & CC & & & & & &,$- 109^{*}$ & & \\
\hline & Sig. & & & & & & .028 & & \\
\hline \multirow[t]{2}{*}{ Edad } & $\mathrm{CC}$ &,$- 103^{*}$ & &,$- 290^{* *}$ &,$- 311^{* *}$ &, $165^{* *}$ &,$- 338^{* *}$ &, $273^{* *}$ &, $100^{*}$ \\
\hline & Sig. & .039 & & .000 & .000 & .001 & .000 & .000 & .045 \\
\hline Nivel educa- & $\mathrm{CC}$ & &, $129^{* *}$ &,$- 240^{* *}$ &,$- 143^{* *}$ &, $119^{*}$ &,$- 230^{* *}$ & ,179** &, $104^{*}$ \\
\hline tivo & Sig. & & .010 & .000 & .004 & .017 & .000 & .000 & .037 \\
\hline \multirow[t]{2}{*}{ Estado civil } & $\mathrm{CC}$ & & &,$- 295^{* *}$ &,$- 289^{* *}$ &, $104^{*}$ &,$- 372^{* *}$ & $193^{* *}$ & \\
\hline & Sig. & & & .000 & .000 & .037 & .000 & .000 & \\
\hline \multirow[t]{2}{*}{ Ocupación } & $\mathrm{CC}$ & & &,$- 211^{* *}$ &,$- 281^{* *}$ & &,$- 294^{* *}$ &, $147^{* *}$ & \\
\hline & Sig. & & & .000 & .000 & & .000 & .003 & \\
\hline \multirow[t]{2}{*}{ Estadía } & $\mathrm{CC}$ & .098 & & $171^{* *}$ & & &, $219^{* *}$ &,$- 098^{*}$ & \\
\hline & Sig. & .050 & & .001 & & & .000 & .050 & \\
\hline \multirow[t]{2}{*}{ Gasto diario } & $\mathrm{CC}$ & & &,$- 235^{* *}$ &,$- 202^{* *}$ &, $124^{*}$ &,$- 315^{* *}$ &, $264^{* *}$ & \\
\hline & Sig. & & & .000 & .000 & .013 & .000 & .000 & \\
\hline Modo de & $\mathrm{CC}$ & & &,$- 109^{*}$ & &, $191^{* *}$ &,$- 099^{*}$ &, $167^{* *}$ &, $120^{*}$ \\
\hline viaje & Sig. & & & .029 & & .000 & .046 & .001 & .016 \\
\hline $\mathrm{N}$ & & 402 & 402 & 402 & 402 & 402 & 402 & 402 & 402 \\
\hline
\end{tabular}

Tabla 8 - Coeficiente de Correlación de Spearman para la variable Grupo de Viaje e indicadores de los factores Co-creación, Entretenimiento y Desarrollo Personal

\begin{tabular}{lcccc}
\hline & $\begin{array}{c}\text { Co-creación [En la provi- } \\
\text { sión/creación/difusión } \\
\text { y/o consumo de servicios } \\
\text { y productos] }\end{array}$ & $\begin{array}{c}\text { Entretenimiento [Na- } \\
\text { turaleza y exteriores] }\end{array}$ & $\begin{array}{c}\text { Desarrollo personal } \\
\text { [Necesidades afec- } \\
\text { tivas cubiertas] }\end{array}$ \\
\hline Grupo de viaje & CC &, $099^{*}$ &,$- 111^{*}$ &, $116^{*}$ \\
& Sig. & .047 & .026 & .020 \\
\hline
\end{tabular}

$\overline{\mathrm{CC}}=$ Coeficiente de correlación; Sig = Sig. (bilateral); ${ }^{* *}$. La correlación es significativa al nivel 0,01 (bilateral);

* La correlación es significativa al nivel 0,05 (bilateral).

Elaboración: Autores

De igual manera se encuentra que la variable gasto diario es influyente en la valoración dada por los turistas a la co-creación; entretenimiento (obtenido con base en naturaleza y exteriores, ambiente de fiesta, shows y conciertos, y arte y cultura); desarrollo personal (basado en aprendizaje y educación, necesidades de autorrealización cubiertas e inteligencia emocional); interacción social; calidad racional (apreciada en función de precios accesibles, confort, facilidad para encontrar lugares, transporte público, atributos del servicio y profesionalismo en el servicio al cliente); así como también en la práctica de valores como la disciplina, integridad y reciprocidad. Los valores del coeficiente de Spearman se muestran en las tablas 9 a la 13 a continuación. 
Tabla 9 - Coeficiente de Correlación de Spearman para la variable Gasto Diario e indicadores del factor Co-creación

\begin{tabular}{lccc}
\hline & & \multicolumn{2}{c}{ Co-creación } \\
& & $\begin{array}{c}\text { En la provisión/creación/di- } \\
\text { fusión y/o consumo de ser- } \\
\text { Vicios y productos }\end{array}$ & $\begin{array}{c}\text { Posibilidad de adaptar el } \\
\text { producto a mis preferen- } \\
\text { cias en tiempo real }\end{array}$ \\
\hline Gasto diario & CC &, $119^{*}$ &, $150^{* *}$ \\
& Sig. & .017 & .003 \\
\hline
\end{tabular}

$\mathrm{CC}=$ Coeficiente de correlación; Sig = Sig. (bilateral); ${ }^{* *}$. La correlación es significativa al nivel 0,01 (bilateral); *. La correlación es significativa al nivel 0,05 (bilateral).

Elaboración: Autores

Tabla 10 - Coeficiente de Correlación de Spearman para la variable Gasto Diario e indicadores del factor Entretenimiento

\begin{tabular}{lccccc}
\hline & & \multicolumn{4}{c}{ Entretenimiento } \\
Variable & & $\begin{array}{c}\text { Naturaleza y } \\
\text { exteriores }\end{array}$ & $\begin{array}{c}\text { Ambiente } \\
\text { de fiesta }\end{array}$ & $\begin{array}{c}\text { Shows y } \\
\text { conciertos }\end{array}$ & Arte y cultura \\
\hline Gasto diario & CC &, $172^{* *}$ &,$- 409^{* *}$ &,$- 207^{* *}$ &, $194^{* *}$ \\
& Sig. & .001 & .000 & .000 & .000 \\
\hline
\end{tabular}

$\mathrm{CC}=$ Coeficiente de correlación; Sig = Sig. (bilateral); ${ }^{* *}$. La correlación es significativa al nivel 0,01 (bilateral); *. La correlación es significativa al nivel 0,05 (bilateral).

Elaboración: Autores

Tabla 11 - Coeficiente de Correlación de Spearman para la variable Gasto Diario e indicadores del factor Desarrollo Personal

\begin{tabular}{|c|c|c|c|c|}
\hline Variable & & $\begin{array}{l}\text { Aprendizaje y } \\
\text { educación }\end{array}$ & $\begin{array}{l}\text { Narrollo personal } \\
\text { autorealización } \\
\text { cubiertas }\end{array}$ & $\begin{array}{c}\text { Inteligencia } \\
\text { emocional }\end{array}$ \\
\hline \multirow[t]{2}{*}{ Gasto diario } & CC & $151^{* *}$ &,$- 119^{*}$ & ,239** \\
\hline & Sig. & .002 & .017 & .000 \\
\hline \multicolumn{5}{|c|}{$\begin{array}{l}\text { CC= Coeficiente de correlación; Sig = Sig. (bilateral); }{ }^{* *} \text {. La correlación es } \\
\text { significativa al nivel } 0,01 \text { (bilateral); }{ }^{*} \text {. La correlación es significativa al nive } \\
0,05 \text { (bilateral). }\end{array}$} \\
\hline \multicolumn{5}{|c|}{ Elaboración: Autores } \\
\hline
\end{tabular}


Tabla 12 - Coeficiente de Correlación de Spearman para la variable Gasto Diario e indicadores de los factores Desarrollo Relacional y Calidad Racional

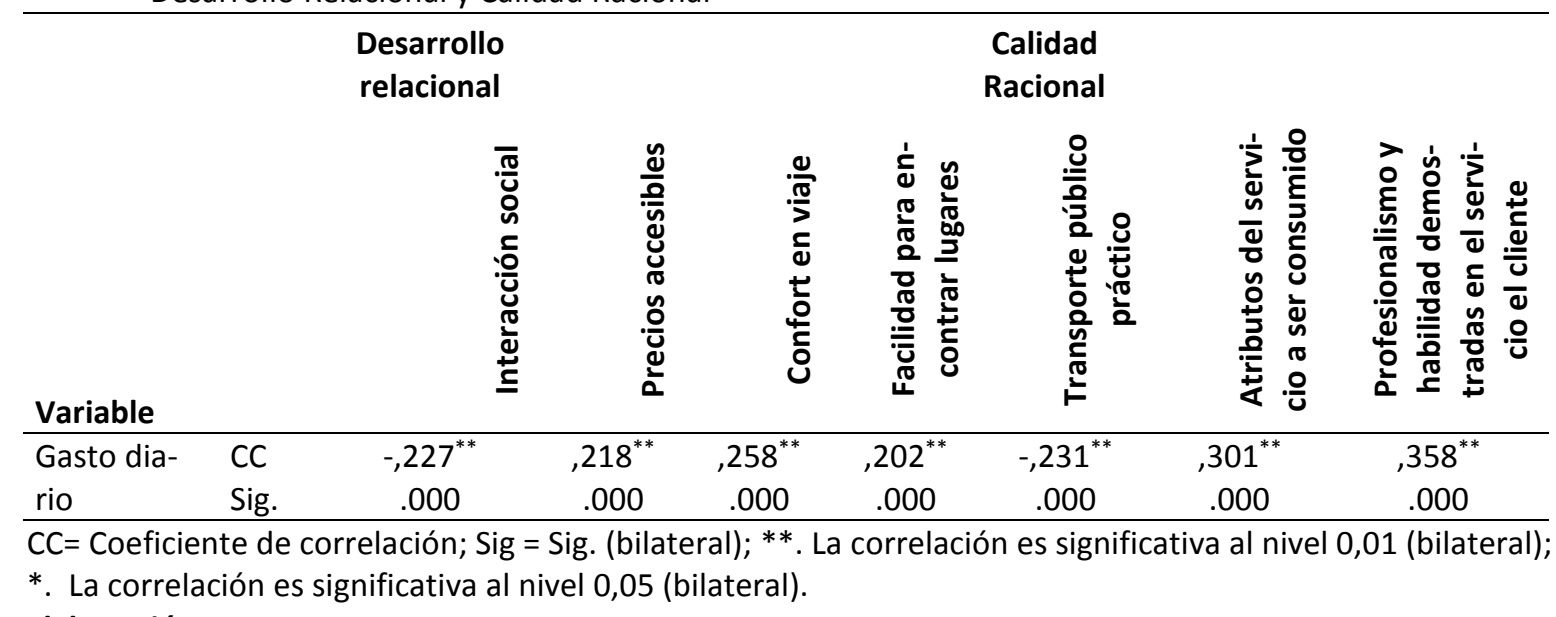

Elaboración: Autores

Tabla 13 - Coeficiente de Correlación de Spearman para la variable Gasto Diario e indicadores del factor Responsabilidad

\begin{tabular}{|c|c|c|c|c|}
\hline \multirow[b]{2}{*}{ Variable } & & \multicolumn{3}{|c|}{ Responsabilidad } \\
\hline & & Integridad & $\begin{array}{l}\text { Disci- } \\
\text { plina }\end{array}$ & $\begin{array}{c}\text { Reciproci- } \\
\text { dad }\end{array}$ \\
\hline \multirow[t]{2}{*}{ Gasto diario } & $\mathrm{CC}$ & $156^{* *}$ & $112^{*}$ & $155^{* *}$ \\
\hline & Sig. & .002 & .025 & .002 \\
\hline
\end{tabular}

La variable estadía en cambio, resultó un aspecto influyente en la valoración de aspectos como: actividades deportivas y recreativas, diversión, ambiente de fiesta y arte y cultura dentro del factor entretenimiento; expandir horizontes, necesidades afectivas y de autorrealización cubiertas e inteligencia emocional, dentro del factor desarrollo per- sonal; interacción social; $y$, precios accesibles, confort, facilidad para encontrar lugares, transporte público practico y profesionalismo en el servicio al cliente, dentro del factor calidad racional. El detalle de los valores calculados para el coeficiente de Spearman se puede ver en las tablas 14 a la 16.

Tabla 14 - Coeficiente de Correlación de Spearman para la variable Estadía e indicadores del factor Entretenimiento

\section{Entretenimiento}

\begin{tabular}{lcccccc} 
Variable & & $\begin{array}{c}\text { Actividades deportivas y } \\
\text { recreativas }\end{array}$ & Diversión & $\begin{array}{c}\text { Ambiente } \\
\text { de fiesta }\end{array}$ & $\begin{array}{c}\text { Shows y } \\
\text { conciertos }\end{array}$ & $\begin{array}{c}\text { Arte y } \\
\text { cultura }\end{array}$ \\
\hline Estadía & CC &, $125^{*}$ &, $111^{*}$ &, $340^{* *}$ &, $199^{* *}$ &,$- 123^{*}$ \\
& Sig. & .012 & .026 & .000 & .000 & .013 \\
\hline
\end{tabular}

$\mathrm{CC}=$ Coeficiente de correlación; Sig = Sig. (bilateral); ${ }^{* *}$. La correlación es significativa al nivel 0,01 (bilateral); ${ }^{*}$. La correlación es significativa al nivel 0,05 (bilateral).

Elaboración: Autores 
Tabla 15 - Coeficiente de Correlación de Spearman para la variable Estadía e indicadores de los factores Desarrollo Personal y Desarrollo Relacional

\begin{tabular}{|c|c|c|c|c|c|c|}
\hline \multirow[b]{2}{*}{ Variable } & & \multicolumn{4}{|c|}{ Desarrollo personal } & \multirow{2}{*}{$\begin{array}{c}\text { Desarrollo } \\
\text { relacional } \\
\text { Interacción } \\
\text { social }\end{array}$} \\
\hline & & $\begin{array}{c}\text { Expandir } \\
\text { horizontes }\end{array}$ & $\begin{array}{c}\text { Necesidades } \\
\text { afectivas } \\
\text { cubiertas }\end{array}$ & $\begin{array}{c}\text { Necesidades de } \\
\text { autorealización } \\
\text { cubiertas }\end{array}$ & $\begin{array}{l}\text { Inteligencia } \\
\text { emocional }\end{array}$ & \\
\hline \multirow[t]{2}{*}{ Estadía } & $\mathrm{CC}$ & $129^{* *}$ & $174^{* *}$ & $121^{*}$ &,$- 140^{* *}$ & $332^{* *}$ \\
\hline & Sig. & .010 & .000 & .015 & .005 & .000 \\
\hline
\end{tabular}

Tabla 16 - Coeficiente de Correlación de Spearman para la variable Estadía e indicadores del factor Calidad Racional

\section{Calidad racional}

\begin{tabular}{lcccccc} 
Variable & Precios & $\begin{array}{c}\text { Confort en } \\
\text { viaje }\end{array}$ & $\begin{array}{c}\text { Facilidad para } \\
\text { encontrar lugares }\end{array}$ & $\begin{array}{c}\text { Transporte } \\
\text { público } \\
\text { práctico }\end{array}$ & $\begin{array}{c}\text { Profesionalismo en } \\
\text { el servicio el cliente }\end{array}$ \\
\hline Estadía & CC &,$- 127^{*}$ &,$- 223^{* *}$ &,$- 145^{* *}$ &, $275^{* *}$ &,$- 165^{* *}$ \\
& Sig. & .011 & .000 & .004 & .000 & .001 \\
\hline
\end{tabular}

$\overline{\mathrm{CC}}=$ Coeficiente de correlación; Sig = Sig. (bilateral); ${ }^{* *}$. La correlación es significativa al nivel 0,01 (bilateral); * La correlación es significativa al nivel 0,05 (bilateral).

Elaboración: Autores

Complementariamente, el estudio muestra que dependiendo la nacionalidad de los turistas, el motivo que les impulsa a contar sus experiencias difiere entre prestigio, orgullo, estatus, honor, respeto y autorealización. Así también, el nivel educativo influye en estos motivos excepto autorealización, donde no se encontró asociación entre variables. El estado civil de los turistas, básicamente muestra su influencia en cuatro de las motivaciones estudiadas: prestigio, orgullo, honor y respeto. Los valores calculados del coeficiente de Spearman se pueden ver en la tabla 17.

Finalmente, el análisis de correlación del conjunto total de indicadores con el indicador particular "sensación de satisfacción", demuestra que los atributos de unicidad del destino constituyen elementos influyentes a nivel de: recursos únicos, historia y singularidad del lugar, clima particular, productos turísticos inimitables, calidad del ambiente único e idiosincrasia única de la gente local.

Así también se confirma que la cocreación influye en la sensación de satisfacción en tanto exista participación en la provisión, creación, difusión y/o consumo de servicios y productos; $y$, se tenga la posibilidad de adaptar el producto a las preferencias del turista en tiempo real. 
Tabla 17 - Coeficiente de Correlación de Spearman para las variables nacionalidad, nivel educativo y Estado Civil vs indicadores del factor Motivaciones

Variable Motivación por:

\begin{tabular}{|c|c|c|c|c|c|c|c|c|c|}
\hline & & $\begin{array}{l}\frac{0}{00} \\
\frac{0.00}{\bar{y}} \\
\frac{0}{2}\end{array}$ & $\begin{array}{l}\stackrel{\circ}{\overline{\bar{g}}} \\
\text { ơ }\end{array}$ & 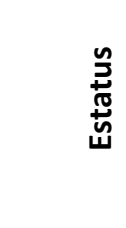 & $\begin{array}{l}\frac{\pi}{0} \\
\frac{0}{0} \\
\frac{0}{2} \\
\frac{\pi}{0} \\
\frac{0}{\alpha}\end{array}$ & $\begin{array}{l}\grave{\vdots} \\
\stackrel{0}{1} \\
\text { 인 }\end{array}$ & 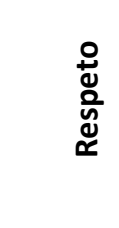 & 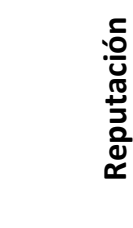 & 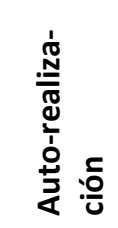 \\
\hline \multirow[t]{2}{*}{ Nacionalidad } & $\mathrm{CC}$ &,$- 249^{* *}$ &,$- 232^{* *}$ &,$- 129^{* *}$ &,$- 142^{* *}$ &,$- 200^{* *}$ &,$- 227^{* *}$ &,$- 274^{* *}$ &,$- 116^{*}$ \\
\hline & Sig. & .000 & .000 & 0.01 & .004 & .000 & .000 & .000 & 0.020 \\
\hline \multirow[t]{2}{*}{ Nivel educativo } & $\mathrm{CC}$ &, $188^{* *}$ &, $167^{* *}$ &, $178^{* *}$ &, $185^{* *}$ &, $180^{* *}$ &, $160^{* *}$ &, $205^{* *}$ & \\
\hline & Sig. & .000 & .001 & .000 & .000 & .000 & .001 & .000 & \\
\hline \multirow[t]{2}{*}{ Estado civil } & $\mathrm{CC}$ & $112^{*}$ & $149^{* *}$ & & & $105^{*}$ &, $119^{*}$ & & \\
\hline & Sig. & .024 & .003 & & & .036 & .017 & & \\
\hline
\end{tabular}

$\mathrm{CC}=$ Coeficiente de correlación; Sig = Sig. (bilateral); ${ }^{* *}$. La correlación es significativa al nivel 0,01 (bilateral); *. La correlación es significativa al nivel 0,05 (bilateral).

Elaboración: Autores

Se encuentra además que aspectos sensación de satisfacción; así como los predel entretenimiento como las actividades de- cios asequibles en el factor calidad racional. portivas y recreativas, naturaleza y exterio- Los valores calculados para el coeficiente de res, diversión, necesidades de afecto y auto- Spearman se muestran a continuación en la realización cubiertas, enriquecimiento cultu- tabla 18, a continuación.

ral e inteligencia emocional, influyen en la 
Tabla 18 - Correlación de Spearman para Satisfacción y variables seleccionadas

\begin{tabular}{|c|c|c|c|}
\hline & Sensación de satisfacción comparada con: & CC. & Sig. \\
\hline \multirow[t]{7}{*}{ Unicidad } & [Recursos únicos] & $194^{* *}$ & .000 \\
\hline & [Historia y singularidad del lugar] &, $182^{* *}$ & .000 \\
\hline & [Clima particular] &, $256^{* *}$ & .000 \\
\hline & [Productos turísticos inimitables] &, $223^{* *}$ & .000 \\
\hline & [Calidad del ambiente único] &, $163^{* *}$ & .001 \\
\hline & [Comidas características del lugar] &, $277^{* *}$ & .000 \\
\hline & [Idiosincrasia única de la gente local] &, $290^{* *}$ & .000 \\
\hline \multirow[t]{2}{*}{ Co-creación } & [Paticipación en la provision, creación, difusión, consumo] &, $171^{* *}$ & .001 \\
\hline & [Posibilidad de adaptar el producto en tiempo real] &, $158^{* *}$ & .001 \\
\hline \multirow[t]{4}{*}{ Entretenimiento } & [Actividades deportivas y recreativas] &, $170^{* *}$ & .001 \\
\hline & [Naturaleza y exteriores] &, $255^{* *}$ & .000 \\
\hline & [Diversión] &, $307^{* *}$ & .000 \\
\hline & [Arte y cultura] &, $348^{* *}$ & .000 \\
\hline \multirow{7}{*}{$\begin{array}{l}\text { Desarrollo } \\
\text { personal }\end{array}$} & [Educación y aprendizaje] &, $225^{* *}$ & .000 \\
\hline & [Interés cultural] &, $224^{* *}$ & .000 \\
\hline & [Expandir horizontes] &, $124^{*}$ & .013 \\
\hline & [Necesidades de afecto cubiertas] &, $193^{* *}$ & .000 \\
\hline & [Necesidades de autorealización cubiertas] &, $132^{* *}$ & .008 \\
\hline & [Enriquecimiento cultural] &, $294^{* *}$ & .000 \\
\hline & [Inteligencia emocional] &, $198^{* *}$ & .000 \\
\hline Calidad racional & [Precios accesibles] &, $170^{* *}$ & .001 \\
\hline
\end{tabular}

$\overline{\mathrm{CC}}=$ Coeficiente de correlación; Sig = Sig. (bilateral); ${ }^{* *}$. La correlación es significativa al nivel 0,01 (bilateral); * La correlación es significativa al nivel 0,05 (bilateral).

Elaboración: Autores

\subsection{Valoración de importancia - desem- peño de la experiencia del turista en Quito}

La valoración de la experiencia del turista en Quito mediante la matriz de importancia - desempeño, muestra que las dimensiones unicidad, multisensorialidad, calidad racional y desarrollo personal se localizan en el primer cuadrante, lo que explica que las experiencia del turista a partir de estas dimensiones se constituye conforme a la importancia dada por el mismo. Dicho en otras palabras, se considera que en estas dimensiones, Quito le ha ofrecido al turista lo que éste ha esperado.
Por otra parte se encuentra que en cuanto a las dimensiones de desarrollo relacional y responsabilidad se ubican en el segundo cuadrante, lo que se traduce como aspectos débiles de la experiencia del turista en el sentido que se visualizan por debajo de sus expectativas. En ese sentido las oportunidades para el desarrollo relacional y la práctica de valores vinculados a la responsabilidad en Quito no han sido las suficientes como para estar a la altura de la importancia que tienen en la óptica del turista que visita la ciudad.

En el tercer cuadrante se posicionan las dimensiones de entretenimiento y cocreación, lo cual indica que estas variables no son consideradas por el turista como muy im- 
portantes y a la vez, tampoco han sido altamente logradas en Quito.

Finalmente, en el cuarto cuadrante se encuentra la dimensión motivación, relacionada al deseo de lograr experiencias dignas de ser comunicadas a los amigos y familiares.
Esto se explica como un aspecto al cual los turistas le otorgan poca importancia pero que sin embargo ha sido percibido con una alta valoración en la ciudad. La figura 2 a continuación expone la matriz de importancia-desempeño.

Figura 2 - Matriz importancia - desempeño de la experiencia del turista en Quito

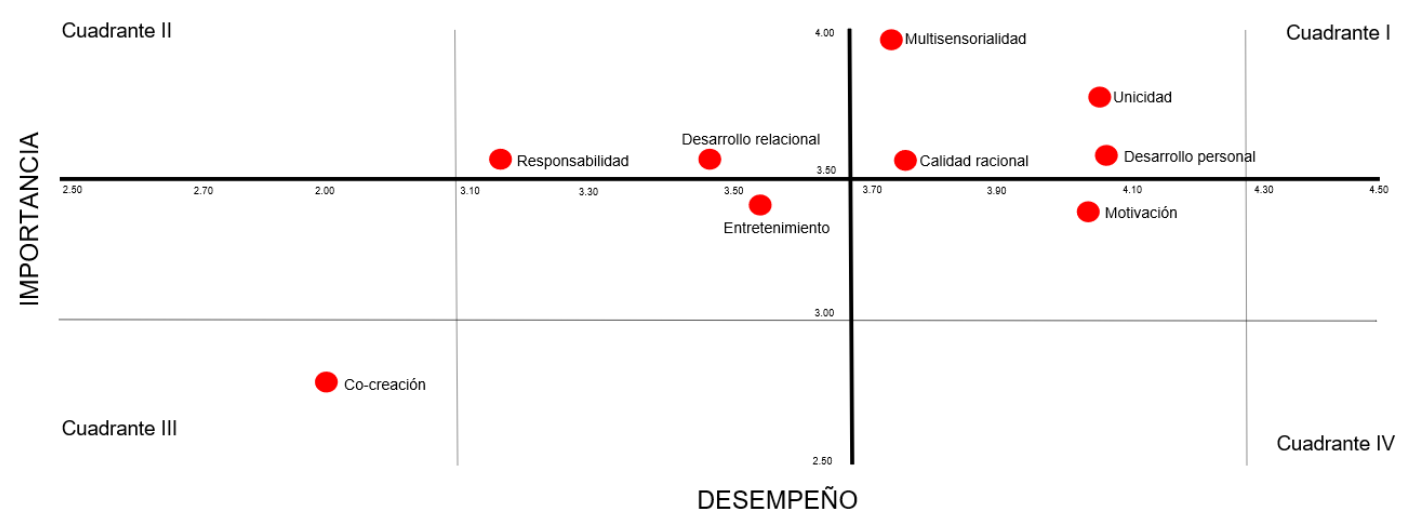

\section{DISCUSIÓN DE RESULTADOS}

Con base en la confirmación de la hipótesis hecha en trabajos previos por los autores Martin, Castellanos y Oviedo (2010); Chen y Chen (2010), Rodríguez, Frías y Castañeda (2012); Naehyun, Lee y Lee (2015); y Cevdet y Erkut (2015); que ubica a la experiencia como un antecedente de la satisfacción del consumidor en turismo, y asumiendo que una experiencia satisfactoria es aquella que produce una sensación de satisfacción alta, se puede colegir en el marco de esta investigación, que la experiencia del turista en Quito es altamente satisfactoria y está vinculada a 5 factores: unicidad, co-creación, entretenimiento, desarrollo personal y calidad racional; medidas por un conjunto de 21 indicadores para los cuales se encontró corre- lación estadística y que son: recursos únicos, historia y singularidad del lugar, clima particular, productos turísticos inimitables, calidad del ambiente, comidas locales, idiosincrasia única de la gente local, participación en servicios y productos, adaptación del producto a las preferencias del turista en tiempo real, actividades deportivas y recreativas, naturaleza y exteriores, diversión, arte y cultura, educación y aprendizaje, interés cultural, expandir horizontes, necesidades de afecto y autorrealización cubiertas, enriquecimiento cultural e inteligencia emocional y precios asequibles.

\section{CONCLUSIONES}

El estudio establece la validez empírica de las dimensiones e indicadores propu- 
estos por los autores Púlido y Navarro (2014), para el contexto de Quito como destino y su demanda turística.

La investigación indica que para los turistas encuestados los factores de la experiencia estudiados no tienen la misma importancia; por el contrario las diferencias estadísticas son significativas en el $87,5 \%$ de las combinaciones pareadas de dimensiones. Esto debe ser entendido teniendo presente el tipo de destino que representa Quito (ciudad) y sus líneas de producto dominantes (urbano y cultural), pues la valoración podría variar en otras tipologías. En este mismo aspecto, cabe considerar que ninguno de los factores obtuvo una valoración muy alta, sino más bien se observó una predominancia de la valoración alta.

Por otra parte se encuentra que las características del turista a nivel de género, edad, nivel educativo, estado civil y ocupación; así como las características de su viaje en términos de estadía, gasto diario y modo de viaje, influyen en la importancia que estos asignan a la mayoría de factores de su experiencia ( 8 de 9), aspectos que representan información valiosa con implicaciones para la estructuración de productos y gestión integral del destino. Encontrando además correlación entre las variables sociodemográficas se observa pertinente la implementación de estrategias diferenciadas considerando el género, edad, nivel educativo, ocupación, nacionalidad y grupo de viaje para estimular la estadía y el gasto promedio diario.

De igual manera el estudio arroja información clave para la gestión, a nivel de indicadores influyentes en la satisfacción del turista. Así, se encuentra que la historia sin- gular de la ciudad, su arte y cultura son muy apreciadas como aspectos de la experiencia turística en Quito, seguidas de las comidas e idiosincrasia locales, mismas que deberían ser salvaguardadas para asegurar su permanencia en el tiempo. En esa misma línea se encuentra atributos de la ciudad y del servicio que deberían mantenerse como son: naturaleza y exteriores, actividades deportivas recreativas, diversión, interacción social, precios, confort, facilidad de localización, cualidades y profesionalismo relacionados al servicio.

En el otro extremo, la participación del turista es el aspecto menos favorable en la ciudad, seguido del transporte público, la atmósfera de fiesta, los conciertos y shows; lo cual marca la pauta para la reflexión de los actores turísticos de la ciudad de cara a emprender acciones correctivas. En un nivel intermedio, es decir oscilando entre una valoración alta y baja, se encuentran la cualidad inimitable del producto turístico y la calidad medioambiental de la ciudad.

Desde una perspectiva integral de importancia - desempeño, la valoración de la experiencia del turista en Quito muestra que en las dimensiones: unicidad, multisensorialidad, calidad racional y desarrollo personal, las expectativas de los turistas se equilibran con lo obtenido durante su viaje; mientras que las dimensiones: desarrollo relacional y responsabilidad se perciben por debajo de sus expectativas.

\section{REFERENCES}

Aho, S. (2001). Towards a general theory of touristic experiences: Modelling experience process in tourism. Tourism Review, 56(3/4), 33-37. 
Bosangit, C., Hibbert, S., \& McCabe, S. (2015). "If I was going to die I should at least be having fun": Travel blogs, meaning and tourist experience. Annals of Tourism Research, 55, 1-14.

Burns, P., \& Holden, A. (1995). Tourism: A new perspective. New Jersey: Prentice Hall. 239.

Carballo, F., Moreno, S., León, C., \& Ritchie, J. (2015). La creación y promoción de experiencias en un destino turístico: un análisis de la investigación y necesidades de actuación. Cuadernos de Turismo, (35), 71-94.

Cetin, G., \& Bilgihan, A. (2015). Components of cultural tourists' experiences in destinations. Current Issues in Tourism, (February), 1-18. doi: 10.1080/13683500.2014.994595

Cevdet, M., \& Erkut, B. (2015). Cultural tourism in Istanbul: The mediation effect of tourist experience and satisfaction on the relationship between involvement and recommendation intention. Journal of Destination Marketing \& Management, Article in press. http://dx.doi.org/10.1016/j.jdmm.2015.06.003i

Chen, C., \& Chen, F. (2010). Experience quality, perceived value, satisfaction and behavioral intentions for heritage tourists. Tourism Management, 31(1), 29-35.

Fusté Forné, F., \& Nava Jiménez, C. (2015). La Experiencia Turística y su Crítica Intercultural. Turismo em Análise, 26(4), 843-858.

Hernández, F., Vargas J., \& Aguilar, J. (2015) El efecto emocional de una experiencia turística: el mercado de artesanías de Oaxaca, México. Cathedra et Scientia. International Journal, 1(1), 147-154.

Hossany, S. \& Gilbert, D. (2014). Measuring Tourists' Emotional Experiences toward Hedonic Holiday Destinations. Journal of Travel Research, 49(4), 513-526.

Hosany, S., \& Witham, M. (2010). Dimensions of cruisers' experiences, satisfaction, and intention to recommend. Journal of Travel Research, 49(3), 351-364.

Ingram, C., Caruana, R., \& McCabe, S. (2017). Participative inquiry for tourist experience Claire. Annals of Tourism Research, 65, 13-24.

Karayilan, E., \& Cetin G. (2016). Tourism Destination: Design of Experiences. En: M. Sotiriadis \& D. Gursoy (Eds.) The Handbook of Managing and Marketing Tourism Experiencies. (pp. 65-84) Bingley: Emerald Group Publishing Limited.

Kim, H., Ritchie, J., \& McCormick, B. (2010). Development of a Scale to Measure Memorable Tourism Experiences. Journal of Travel Research, 51(1), 12-25.

Kim, J. (2014). The antecedents of memorable tourism experiences: The development of a scale to measure the destination attributes associated with memorable experiences. Tourism Management, 44, 34-45.

Larsen, S. (2007). Aspects of a Psychology of the Tourist Experience. Scandinavian Journal of Hospitality and Tourism, 7(1), 7-18.

Martin, D., Castellanos, M., \& Oviedo, M. (2010). A visitor's evaluation index for a visit to an archaeological site. Tourism Management, 31(5), 590-596

Mendes, J., Valle, P., Guerreiro, M., \& Silva, J. (2010). The tourist experience: Exploring the relationship between tourist satisfaction and destination loyalty. Tourism, 58(2), 111-126.

Naehyun, J., Lee, S., \& Lee, H. (2015). The effect of Experience Quality on Perceived Value, Satisfaction, Image and Behavioral Intention of Water Park Patrons: New versus Repeat Visitors. Internacional Journal od Tourism Research, 17: 8295. doi: $10.1002 /$ jtr.1968

Nunnally, J., \& Bernstein, I. (1994). Psychometric theory (3rd ed.). New York: McGraw Hill

Oakeshot, M. (1933) Experiences and its modes. 
Cambridge Philosophy Classics Edition, Cambridge: Cambridge University Press.

Otto, J., \& Ritchie, J. (1996). The service experience in tourism. Tourism Management, 17(3), 165-174.

Park, S. \& Almeida, C. (2016) Exploring the Tourist Experience: A Sequential Approach. Journal of Travel Research, (January), 1-12.

Pine, J., \& Gilmore, J. (1998). Welcome to the Experience Economy. Harvard Business Review, 76(4), 97-105.

Prayag, G., Hosany, S., \& Odeh, K. (2013). The role of tourists' emotional experiences and satisfaction in understanding behavioral intentions. Journal of Destination Marketing \& Management, 2, 118-127.

Pulido, J., \& Navarro, U. (2014). Identificación de ítems para medir las experiencias del turista en destino. Cultur, Revista de Cultura e Turismo, 8(1), 4-34.

Rodríguez, M., Frías, D., \& Castañeda, J. (2013). The moderating role of past experience in the formation of a tourist destination's image and in tourists' behavioural intentions. Current Issues in Tourism, 16(2), $107-127$. doi: $10.1080 / 13683500.2012 .665045$

Ryan, C. (2010). Ways of Conceptualizing the Tourist Experience: A Review of Literature. Tourism Recreation Research, 35(1), 37-46

Rivera, M. (2013). El turismo experiencial como forma de turismo responsable e intercultural. Universidad de Córdova, Cátedra Intercultural (Eds). Jornadas sobre Investigación e Innovación para la Interculturalidad. (pp. 199-217) Córdoba, España
Sernatur (2016). Manual de Diseño Experiencias Turísticas. Verde Ltda. Santiago, Chile. 103 p.

Sharpley, R., \& Stone, P. (2011). Introduction: Thinking about the tourist experience. En: R. Sharpley \& P. R. Stone (Eds.), Tourism experience; contemporary perspectives, (pp.1-8). Abingdon, Oxon: Routledge.

Tussyadiah, L. (2014). Toward a Theoretical Foundation for Experience Design in Tourism. Journal of Travel Research, 53(5), 543-564

Wearing, S., \& Foley, C. (2017). Understanding the tourist experience of cities. Annals of Tourism Research, 65, 97-107.

$\overline{\text { Datos de los autores }}$

Pablo Torres Matovelle es profesor de la Maestría en Destinos Sostenibles en la Universidad Tecnológica Israel, Quito, Ecuador. Posee estudios superiores de turismo en la Escuela Superior Politécnica de Chimborazo y una Maestría en Gerencia Empresarial en la Escuela Politécnica Nacional, ambos centros de educación de Ecuador. Además es candidato a PhD., en la Universidad de la Habana, Cuba. Sus principales áreas de interés académico incluyen: competitividad de destinos turísticos, planificación y gestión de destinos, impactos socioculturales del desarrollo turístico, seguridad en el turismo, comportamiento del turista, manejo del turismo cultural y patrimonial, turismo con base local y turismo sostenible. E-mail: pablotorresmatovelle@gmail.com / pablo t@ftur.uh.cu - ORCID: 0000-0001-9634-6353

Simone Baez es Ingeniera en Administración de Empresas Turísticas y Conservación Ambiental, graduada en la Universidad Tecnológica Equinoccial en Quito, Ecuador. Sus principales áreas de interés académico son la experiencia del turista y el turismo cultural. Email: simone baez18@hotmail.com. ORCID: 00000003-1261-757X 